\title{
EFEITO DE HERBICIDAS DE PÓS-EMERGÊNCIA, APLICADOS EM VÁRIAS ÉPOCAS, COMPARADOS COM ATRAZINE+METOLACHLOR, EM PRÉ-EMERGÊNCIA, NA CULTURA DO MILHO
}

\author{
Antônio Carlos de Barros ${ }^{1}$, Akira Ueda ${ }^{2}$ e Karl C. Schumm²
}

${ }^{1}$ Agência Rural. Caixa Postal 211. Jataí, GO 75800-069
${ }^{2}$ Novartis. Caixa Postal 21460. São Paulo, SP 04602-970

\section{RESUMO}

O trabalho foi conduzido com o objetivo de avaliar a eficiência de herbicidas de pós-emergência, aplicados em várias épocas, comparados com atrazine+metolachlor, em pré-emergência, e os efeitos sobre algumas características agronômicas do milho. O ensaio foi conduzido no município de Rio Verde-GO, na safra 1997/98. O híbrido utilizado foi AG-5011, semeado em 26/10/97 e os tratamentos utilizados foram: atrazine+metolachlor $(1400+2100 \mathrm{~g} / \mathrm{ha})$, aplicado em pré-emergência; atrazine/metolachlor+nicosulfuron $(1000 / 1500+12 \mathrm{~g} / \mathrm{ha})$, aplicados em pós-emergência precoce; atrazine/óleo vegetal+nicosulfuron $(1600+20 \mathrm{~g} / \mathrm{ha})$, em pós-emergência normal; atrazine+nicosulfuron $(1000+40 \mathrm{~g} / \mathrm{ha})$, em pós-emergência tardia; nicosulfuron ( $50 \mathrm{~g} / \mathrm{ha}$ ), em pós-emergência avançada, além das testemunhas com e sem capina. Verificou-se que os herbicidas proporcionaram eficiente controle da corda-de-viola (Ipomoea grandifolia), leiteiro (Euphorbia heterophylla) e trapoeraba (Commelina benghalensis). Nicosulfuron $(50 \mathrm{~g} / \mathrm{ha}$ ) não controlou C. benghalensise e todos os herbicidas foram seletivos para a cultura do milho. A aplicação dos tratamentos não afetou significativamente a população final e altura da primeira espiga, porém, nicosulfuron isolado proporcionou altura de planta estatisticamente inferior a atrazine/ metolachlor+nicosulfuron. $\mathrm{O}$ índice de colheita mecânica nos tratamentos químicos foi excelente, exceto para nicosulfuron, que foi médio. Nas testemunhas com e sem capina este índice foi excelente e difícil, respectivamente. Isto ficou evidenciado no peso de matéria seca das plantas daninhas, sendo o maior peso observado na testemunha sem capina.

Palavras-chave: nicosulfuron, óleo vegetal, época de aplicação, Ipomoea grandifolia, Euphorbia heterophylla, Commelina benghalensis.

\section{ABSTRACT \\ Effect of postemergence herbicides, applied at different weed stages, compared to atrazine+metolachlor in corn}

The experiment was carried out during 1997/98, in Rio Verde (GO), to evaluate the efficacy of postemergence herbicides, applied at different times, compared to atrazine+metolachor applied at preemergence. The effect of these herbicides on some agronomic characteristics of corn was also evaluated. The hybrid corn used was AG-5011, sown on 10/26/97, and the treatments were: postemergence application of atrazine+metolachlor $(1400+2100 \mathrm{~g} / \mathrm{ha})$, early postemergence application of atrazine/metolachlor+nicosulfuron $(1000 / 1500+12 \mathrm{~g} / \mathrm{ha})$, postermergence aplication of atrazine vegetal oil+nicosulfuron $(1600+20 \mathrm{~g} / \mathrm{ha})$, late postemergence application of atrazine+nicosulfuron $(1000+40 \mathrm{~g} / \mathrm{ha})$, late aplication of nicosulfuron $(50$ g/ha) and two controls: with and without hoeing. The herbicides controlled Ipomoea grandifolia, Euphorbia heteroplylla and Commelina benghalensis. Only nicosulfuron $(50 \mathrm{~g} / \mathrm{ha})$ did not control C. benghalensis. Final stand and height of first corn ear were not affected by the herbicibes. Nicosulfuron $(50 \mathrm{~g} / \mathrm{ha})$ however affected plant height. The index of mechanical 
harvest was excellent, except for crops which received nicosulfuron. This index was excellent and difficult, respectively, for the control with hoeing and without hoeing. The weed dry weight was higher in the control without hoeing.

Key words: vegetal oil, time of application, Ipomoea grandifolia, Euphorbia, heteroplylla, Commelina benghalensis.

\section{INTRODUÇÃO}

A cultura do milho, apesar de ser considerada eficiente na competição, sofre interferência das plantas daninhas, que pode prejudicar o crescimento, a produção de grãos e a operação de colheita mecânica. Portanto, a eliminação da vegetação daninha consiste em uma prática indispensável para se obter maiores níveis de produtividade dessa cultura (Rossi et al., 1996).

Ruckhein Filho \& Venturella (1977) relatam que o período crítico de competição do milho vai desde a emergência até 45 a 50 dias do ciclo. Silva \& Silva (1997) afirmam que a cultura do milho não deve sofrer interferência das plantas daninhas até o pendoamento, para evitar prejuízos à produtividade de grãos. Por outro lado, a interferência das plantas daninhas sobre a cultura do milho é variável durante o ciclo dessa cultura. Kapusta et al. (1994), citado por Merotto Júnior et al. (1997), observaram que o rendimento de grãos do milho está mais relacionado com a duração da competição do que com a eficiência do controle das plantas invasoras.

No ecossistema Cerrado tem sido grande a diversidade de espécies de plantas daninhas que infestam as lavouras de milho. Segundo Barros (1993), no Estado de Goiás tem sido freqüente a trapoeraba, o leiteiro, a corda-de-viola, dentre outras, as quais em determinadas situações podem causar consideráveis prejuízos à cultura do milho.

Portanto, para evitar perdas na produtividade do milho, o principal método utilizado pelo agricultor, tem sido o controle químico da comunidade infestante. Produtos tradicionalmente utilizados em pré-emergência, como as misturas de atrazine+metolachlor, atrazine+alachlor e atrazine+simazine, dentre outras, tem proporcionado controle eficiente da maioria das espécies infestantes e apresentado seletividade para o milho, conforme atestam, Barros \& Oliveira (1990), Barros \& Mendonça (1991), Forster (1991), Barros (1998) e Santos \& Rozanski (s.d.).

Também tem sido empregados alguns ingredientes ativos em pós-emergência precoce, destacando-se atrazine, que tem proporcionado bons níveis de controle de plantas invasoras dicotiledôneas (Barros, 1994).

Com o registro do herbicidas nicosulfuron no Brasil, abriram-se novas perspectivas para o controle das plantas daninhas na cultura do milho. Nicosulfuron é um herbicida pertecente ao grupo químico sulfoniluréia, que é um inibidor de ALS (acetolactato sintase), impedindo a síntese de aminoácidos essenciais: valina, leucina e isoleucina (Vidal, 1997). Trata-se de um produto com mecanismo de ação to- talmente diferente dos herbicidas tradicionalmente utilizados nessa cultura, propiciando o emprego racional de combinações de herbicidas.

Em função da grande diversidade de espécies de plantas daninhas, tem sido necessário o uso de misturas de herbicidas, as quais tem favorecido uma ampla faixa de controle da vegetação daninha.

O objetivo do trabalho foi avaliar a eficácia agronômica de misturas em tanque de herbicidas, aplicadas em diferentes estágios de desenvolvimento das plantas daninhas, comparando-as com atrazine+metolachlor, aplicada em pré-emergência, bem como a possível fitotoxicidade à cultura do milho e os efeitos sobre algumas características agronômicas dessa cultura.

\section{MATERIAL E MÉTODOS}

O experimento foi conduzido no município de Rio Verde (GO), no ano agrícola 1997/98, em solo classificado como Latossolo vermelho-escuro, distrófico, contendo 38\% de argila e 2,6\% de matéria orgânica.

O delineamento experimental adotado foi o de blocos ao acaso, com sete tratamentos e quatro repetições. Os tratamentos utilizados foram: 1) atrazine+metolachlor $(1400+2100$ $\mathrm{g} / \mathrm{ha}$ ), aplicados em pré-emergência; 2) atrazine/ metolachlor+nicosulfuron $(1000 / 1500+12 \mathrm{~g} / \mathrm{ha})$, aplicados em pós-emergência precoce (pós-p), com as plantas daninhas até 2 folhas; 3$)$ atrazine/óleo vegetal+nicosulfuron $(1600+20$ $\mathrm{g} / \mathrm{ha}$ ), com a aplicação em pós-emergência normal (pós-p), quando as plantas invasoras possuíam até 4 folhas; 4) atrazine+nicosulfuron $(1000+40 \mathrm{~g} / \mathrm{ha})$, em pós-emergência tardia (pós-t), com a vegetação daninha até 6 folhas; 5) nicosulfuron (50 g/ha), em pós-emergência avançada (pósa), com as plantas daninhas até 8 folhas; 6 ) testemunha capinada e 7) testemunha sem capina.

O milho híbrido AG-5011 foi semeado em 26/10/97, recebendo nos sulcos de plantio a adubação de $300 \mathrm{~kg} / \mathrm{ha}$ da fórmula 8-30-16+Zn. A adubação nitrogenada de cobertura foi efetuada aos 25 dias após a emergência do milho, com uréia, empregando-se $45 \mathrm{~kg} / \mathrm{ha}$ de $\mathrm{N}$.

O sistema de preparo do solo utilizado foi o convencional, sendo realizada uma aração e duas gradagens, a última um dia antes da semeadura desse cereal. No período do preparo do solo, o mesmo apresentava umidade adequada.

As parcelas experimentais mediram $10 \mathrm{~m}$ de comprimento por $3 \mathrm{~m}$ de largura, perfazendo um total de $30 \mathrm{~m}^{2}$. A área útil para observações mediu $8 \mathrm{~m} \mathrm{x} 2 \mathrm{~m}$, totalizando 16 
Efeito de herbicidas de pós-emergência...

$m^{2}$.

Os herbicidas foram aplicados por meio de um pulverizador costal, pressurizado a $\mathrm{CO}_{2}$, pontas de pulverização (bicos) tipo leque 110.02 , calibrado para $3 \mathrm{~kg} / \mathrm{cm}^{2}$ de pressão, consumindo 200 litros de calda/ha.

O controle das plantas daninhas foi avaliado aos 15 , 30 e 45 dias após a aplicação dos tratamentos (DAT), adotando-se a escala percentual, sendo zero correspondente a nenhum controle e cem equivalente a controle total das plantas infestantes. Na mesma época foi avaliada a toxicidade sobre as plantas de milho, adotando-se, também, a escala percentual descrita acima.

$\mathrm{Na}$ colheita do milho, mediram-se as alturas de plantas e de inserção da primeira espiga, além de serem avaliadas a população final do milho, o peso da matéria seca das plantas daninhas e o rendimento de grãos. Foi avaliado, ainda, o índice de colheita mecânica, levando-se em consideração o grau de infestação das parcelas experimentais, além do porte das plantas daninhas, adotando-se a escala arbitrária: excelente, bom, médio, difícil e impossível.

Os parâmetros população final, altura de plantas e de inserção da primeira espiga, peso da biomassa das plantas daninhas e o rendimento de grãos, foram submetidos à análise de variância e as médias comparadas pelo teste de Tukey a $5 \%$ de probabilidade.

\section{RESULTADOS E DISCUSSÃO}

O complexo florístico das plantas invasoras na área experimental era constituído por corda-de-viola (Ipomoea grandifolia), com a densidade populacional média de 21 plantas $/ \mathrm{m}^{2}$, leiteiro (Euphorbia heterophylla), com 15 plantas $/ \mathrm{m}^{2}$ e trapoeraba (Commelina benghalensis), com 13 plantas/ $\mathrm{m}^{2}$.

Os maiores níveis de controle da corda-de-viola foram obtidos pelas misturas em tanque de atrazine/óleo vegetal+nicosulfuron $(1600+20 \mathrm{~g} / \mathrm{ha})$, aplicadas em pós-emergência-normal (pós-n); atrazine+nicosulfuron $(1000+40 \mathrm{~g} /$ ha), em pós-emergência-tardia (pós-t); atrazine/ metolachlor+nicosulfuron $(1000 / 1500+12 \mathrm{~g} / \mathrm{ha})$, aplicadas em pós-emergência-precoce (pós-p) e atrazine+metolachlor $(1400+2100 \mathrm{~g} / \mathrm{ha})$, em pré-emergência (prê-e), com controle variando de 87 a 97\%, aos 45 DAT (Tabela 1).

Nicosulfuron (50 g/ha) aplicado em pós-emergênciaavançada (pós-a), propiciou controle satisfatório da cordade-viola, aos 45 DAT (83\%). Porém, tal controle foi insuficiente, pois trata-se de uma espécie bastante freqüente nas lavouras e terminando o ciclo após a maturação das culturas, tendendo a causar problemas na colheita, quando a infestação é significativa, pois seus ramos se emaranham nas plantas da cultura (Kissmann, 1992).

Os índices de controle da corda-de-viola, proporcionaods pelas misturas em tanque de atrazine/óleo vegetal+nicosulfuron (pós-n), atrazine+nicosulfuron (pós-t), além de atrazine/metolachlor+nicosulfuron (pós-p), foram considerados excelentes, obtendo-se controle mínimo de $94 \%$, aos 45 DAT.

A aplicação de atrazine+metolachlor (pré-e), apesar de ter proporcionado controle eficiente da corda-de-viola (87\%), aos 45 DAT, tal resultado foi inferior àqueles obtidos nos tratamentos contendo produtos aplicados em pós-emergência-precoce, ou pós-emergência-normal ou ainda de pósemergência-tardia. Carvalho et al. (1997), em ensaio com herbicidas aplicados em pré-emergência na cultura do milho, também observaram que a mistura formulada de atrazine/ metolachlor (1200/1800 g/ha), proporcionou eficiente controle da corda-de-viola.

Quanto ao leiteiro, os tratamentos químicos proporcionaram níveis de controle iguais ou superiores a $90 \%$ (Tabela 1). Já atrazine+metolachlor $(1400+2100 \mathrm{~g} / \mathrm{ha})$, em pré-e, propiciou controle inferior do leiteiro $(84 \%)$ aos 45 DAT, porém aceitável na prática. Por outro lado, a aplicação de atrazine/metolachlor (1000/1500 g/ha), na mistura em tanque com nicosulfuron (12 g/ha) em pós-p, proporcionou índice de controle superior do leiteiro, quando comparado com atrazine+metolachlor $(1400+2100 \mathrm{~g} / \mathrm{ha})$ em pré-emergência. Queiroz et al. (1997), também conseguiram bom controle de leiteiro com o uso de atrazine+metolachlor $(1200+1800 \mathrm{~g} /$ ha), aplicados em pré-emergência.

O controle da trapoeraba foi inferior $(78 \%)$ com $50 \mathrm{~g} /$ ha de nicosulfuron (pós-a), aos 45 DAT, enquanto atrazine/ metolachlor+nicosulfuron (pós-p), atrazine/óleo

Tabela 1 . Resultados médios de controle das plantas daninhas, obtidos com herbicidas aplicados em diferentes épocas, na cultura do milho. Rio Verde, GO. 1997/98.

\begin{tabular}{|c|c|c|c|c|c|c|c|c|c|c|c|}
\hline \multirow{3}{*}{ TRATAMENTO } & \multirow{3}{*}{$\begin{array}{l}\text { DOSE } \\
(\mathrm{g} / \mathrm{ha})\end{array}$} & \multirow{3}{*}{$\begin{array}{c}\text { ÉPOCA } \\
\text { DE } \\
\text { APLICAÇÃO }\end{array}$} & \multicolumn{9}{|c|}{ CONTROLE $(\%)$} \\
\hline & & & \multicolumn{3}{|c|}{$\begin{array}{l}\text { I. grandifolia } \\
\text { DAT }\end{array}$} & \multicolumn{3}{|c|}{$\begin{array}{c}E . \text { heterophylla } \\
\text { DAT }\end{array}$} & \multicolumn{3}{|c|}{$\begin{array}{c}\text { C. benghalensis } \\
\text { DAT }\end{array}$} \\
\hline & & & 15 & 30 & 45 & 15 & 30 & 45 & 15 & 30 & 45 \\
\hline Atrazine + metolachlor & $1400+2100$ & Pré-emergência & 88 & 87 & 87 & 88 & 84 & 84 & 95 & 94 & 93 \\
\hline Atrazine/metolachlor+nicosulfuron & $100 / 1500+12$ & Pós-precoce & 92 & 93 & 94 & 92 & 90 & 90 & 96 & 93 & 92 \\
\hline Atrazine/óleo+nicosulfuron & $1600+20$ & Pós-normal & 95 & 96 & 97 & 95 & 95 & 96 & 98 & 92 & 95 \\
\hline Atrazine + nicosulfuron & $1000+40$ & Pós-tardia & 94 & 95 & 95 & 94 & 95 & 96 & 98 & 93 & 94 \\
\hline Nicosulfuron & 50 & Pós-avançada & 84 & 84 & 83 & 90 & 90 & 90 & 79 & 78 & 78 \\
\hline Testemunha capinada & -- & -- & 100 & 100 & 100 & 100 & 100 & 100 & 100 & 100 & 100 \\
\hline Testemunha sem capina & -- & -- & 0 & 0 & 0 & 0 & 0 & 0 & 0 & 0 & 0 \\
\hline
\end{tabular}

Revista Brasileira de Herbicidas, v.1, n.3, 2000. 
Antônio Carlos de Barros et al.

vegetal+nicosulfuron (pós-n), atrazine+nicosulfuron (pós-t), além de atrazine +metolachlor (pré-e) proporcionaram eficiente controle da referida espécie infestante (Tabela 1).

Para o controle das plantas daninhas dicotiledôneas, as aplicações dos herbicidas em pós-emergência tardia não apresentaram diferenças acentuadas no controle da comunidade infestantes, possivelmente ocasionado pelo intervalo da aplicação dos produtos muito curto, com variação de 2 a 6 folhas das plantas invasoras.

O nicosulfuron, apesar de ter sido aplicado em estádio mais avançado das plantas daninhas (até 8 folhas), proporcionou bom controle do leiteiro e controle satisfatório da corda-de-viola, porém inferior no caso da trapoeraba.

As precipitações pluviais ocorridas no período de condução do ensaio, foram consideradas normais para a região, proporcionando desenvolvimento normal à cultura do milho (Tabela 2).

Com relação à toxicidade, observou-se que, os herbicidas provocaram injúrias iniciais leves às plantas de milho, com rápida recuperação já aos 30 DAT (Tabela 3). Portanto, nas doses testadas, os herbicidas foram seletivos para a cultura do milho. Fahal e Carelli (1997), não observa-

Tabela 2. Precipitações pluviais registradas no Centro de Ciências Agrárias da UFG, em Jataí (GO), no período de outubro/97 a março/98.

\begin{tabular}{|c|c|c|c|c|c|c|}
\hline \multirow[t]{2}{*}{ DIAS } & \multicolumn{3}{|c|}{1997} & \multicolumn{3}{|c|}{1998} \\
\hline & OUT. & Nov. & DEZ. & JAN. & FEV. & MAR. \\
\hline 1 & 8,3 & 21,2 & 0,0 & 5,0 & 26,9 & 0,6 \\
\hline 2 & 0,1 & 16,7 & 71,4 & 2,9 & 23,4 & 4,4 \\
\hline 3 & 0,0 & 0,0 & 4,0 & 0,0 & 20,7 & 13,6 \\
\hline 4 & 0,0 & 0,9 & 3,8 & 8,0 & 5,2 & 0,1 \\
\hline 5 & 0,0 & 0,0 & 19,9 & 0,0 & 0,0 & 21,7 \\
\hline 6 & 0,0 & 5,1 & 0,0 & 0,0 & 0,2 & 29,4 \\
\hline 7 & 0,3 & 19,8 & 0,6 & 1,6 & 0,8 & 1,8 \\
\hline 8 & 0,0 & 0,0 & 0,0 & 1,2 & 0,0 & 0,0 \\
\hline 9 & 0,0 & 0,0 & 1,5 & 1,6 & 0,2 & 2,4 \\
\hline 10 & 0,0 & 3,8 & 36,4 & 4,4 & 0,0 & 17,1 \\
\hline 11 & 0,0 & 0,0 & 6,2 & 0,4 & 3,9 & 0,3 \\
\hline 12 & 0,0 & 0,0 & 13,5 & 0,0 & 28,1 & 0,0 \\
\hline 13 & 0,0 & 0,0 & 0,0 & 0,7 & 4,6 & 0,0 \\
\hline 14 & 0,0 & 9,9 & 0,8 & 46,3 & 35,4 & 3,6 \\
\hline 15 & 0,0 & 22,6 & 12,2 & 0,1 & 0,5 & 10,9 \\
\hline 16 & 0,0 & 1,9 & 0,5 & 0,0 & 7,0 & 11,5 \\
\hline 17 & 0,0 & 3,5 & 0,0 & 9,3 & 0,1 & 17,6 \\
\hline 18 & 0,0 & 0,4 & 0,0 & 0,9 & 10,0 & 14,0 \\
\hline 19 & 16,3 & 27,3 & 0,6 & 25,0 & 0,0 & 19,4 \\
\hline 20 & 16,1 & 0,0 & 0,0 & 0,7 & 0,0 & 0,0 \\
\hline 21 & 20,6 & 0,0 & 1,5 & 1,4 & 8,0 & 27,0 \\
\hline 22 & 3,0 & 16,7 & 4,4 & 3,0 & 23,3 & 0,0 \\
\hline 23 & 0,0 & 0,2 & 0,0 & 2,0 & 88,8 & 0,0 \\
\hline 24 & 0,0 & 1,4 & 62,3 & 2,6 & 2,1 & 0,0 \\
\hline 25 & 0,0 & 5,5 & 0,0 & 2,6 & 0,3 & 0,0 \\
\hline 26 & 0,3 & 0,6 & 1,5 & 0,0 & 0,0 & 32,0 \\
\hline 27 & 10,3 & 0,0 & 0,2 & 3,4 & 3,9 & 0,0 \\
\hline 28 & 0,0 & 16,5 & 3,3 & 0,2 & 7,8 & 13,8 \\
\hline 29 & 0,0 & 15,0 & 0,0 & 2,0 &.- & 3,4 \\
\hline 30 & 35,6 & 31,7 & 0,0 & 33,8 & -- & 0,0 \\
\hline 31 & 0,0 & -- & 20,4 & 0,4 & -. & 4,7 \\
\hline Total & 110,9 & 220,7 & 265,0 & 159,5 & 275,1 & 275,6 \\
\hline
\end{tabular}

ram intoxicação à cultura do milho causado pelo nicosulfuron em doses variando de 40 a $80 \mathrm{~g} / \mathrm{ha}$. No entanto, Barros (1998) observou sintomas de fitointoxicação inicial leve à cultura do milho, com o uso de atrazine+metolachlor $(1200+1800 \mathrm{~g} /$ ha), em ensaio com herbicidas em pré-emergência, conduzido em Jataí-GO.

No final do ciclo do milho, verificou-se que os tratamentos atrazine+metolachlor (pré-e); atrazine/óleo vegetal+nicosulfuron (pós-n); atrazine/metolachlor +nicosulfuron(pós-p)e atrazine+nicosulfuron (pós-t), além da testemunha capinada, proporcionaram índice de colheita mecânica excelente (Tabela 4). Nicosulfuron (pós-a) apresentou índice de colheita médio, enquanto que na testemunha sem capina, foi considerado difícil, ocasionado principalmente pela presença da corda-de-viola. Esta é uma planta que apresenta intenso crescimento vegetativo, enrolando na planta de milho, podendo atingir até a inflorescência masculina do milho, dificultando consideravelmente a colheita mecânica.

Quanto a população final e altura da inserção da primeira espiga, não foram observadas diferenças significativas entre os tratamentos químicos e as testemunhas com e sem capina (Tabela 4).

Para a altura de plantas, verificou-se que o herbicida nicosulfuron, aplicado isolado, em pós-emergência avançada, proporcionou a menor altura de plantas de milho, porém, não diferindo estatisticamente dos outros tratamentos, exceto de atrazine/metolachlor+nicosulfuron, aplicados em pósemergência precoce, com maior altura (Tabela 4).

A maior biomassa seca das plantas daninhas foi obtida na testemunha sem capina $\left(336,5 \mathrm{~g} / \mathrm{m}^{2}\right)$, estatisticamente superior a todos os outros tratamentos (Tabela 5). No entanto, o menor peso de matéria seca foi obtido na testemunha capinada, porém não diferindo estatisticamente dos outros tratamentos químicos, exceto para o tratamento contendo nicosulfuron isolado, aplicado em pós-emergência avançada. Verifica-se ainda, que ao avaliar a matéria seca nos diferentes tratamentos químicos, não houve diferenças estatísticas entre as aplicações de herbicidas em pré-emergência e as de pós-emergência precoce ou pós-emergência normal ou de pós-emergência tardia.

O tratamento contendo atrazine+metolachlor (pré-e), apresentou controle ligeiramente inferior de duas espécies infestantes, até 45 DAT, porém, a biomassa seca foi semelhante estatisticamente aos tratamentos de pós-p, pós-n e póst. Isso possivelmente foi ocasionado pela emergência das plantas infestantes no tratamento atrazine+metolachlor (pré-e). Todavia, essas plântulas apresentaram sintomas de intoxicação causadas pelos herbicidas, dificultando o desenvolvimento vegetativo das mesmas, o que contribuiu para a reduzida biomassa seca.

Quanto ao rendimento de grãos, não foram observadas diferenças significativas entre os tratamentos químicos e nem com a testemunha capinada (Tabela 5). No entanto, a produção de grãos obtida no tratamento atrazine/óleo vegetal+nicosulfuron $(1600+20 \mathrm{~g} / \mathrm{ha})$, em pós-n, foi $7,9 \%$ superior em relação a atrazine+metolachlor $(1400+2100 \mathrm{~g} /$ 
Efeito de herbicidas de pós-emergência...

Tabela 3. Resultados médios de toxicidade, obtidos no ensaio de herbicidas na cultura do milho. Rio Verde, GO. 1997/1998.

\begin{tabular}{|c|c|c|c|c|c|}
\hline \multirow{3}{*}{ TRATAMENTO } & \multirow{3}{*}{$\begin{array}{l}\text { DOSE } \\
(\mathrm{g} / \mathrm{ha})\end{array}$} & \multirow{3}{*}{$\begin{array}{c}\text { EPOCA } \\
\text { DE } \\
\text { APLICAÇÃO }\end{array}$} & \multicolumn{3}{|c|}{ TOXICIDADE $^{1}(\%)$} \\
\hline & & & \multicolumn{3}{|c|}{$\overline{\mathrm{DAT}}$} \\
\hline & & & 15 & 39 & 45 \\
\hline Atrazine + metolachl or & $1400+2100$ & Pré-emergên cia & 5 & 0 & 0 \\
\hline Atrazine $/ \mathrm{m}$ etola chlor + ni cosulfur on & $100 / 1500+12$ & Pós-emergência & 10 & 0 & 0 \\
\hline Atrazine/óleo+nicosulfuron & $1600+20$ & Pós-ormal & 8 & 0 & 0 \\
\hline Atrazine + nicosulfuron & $1000+40$ & Pós-tardio & 8 & 0 & 0 \\
\hline Nicosulfur on & 50 & Pós-avançado & 10 & 0 & 0 \\
\hline Testemunha capinada & -- & -. & 0 & 0 & 0 \\
\hline Testemunha sem capina & -. & -. & 0 & 0 & 0 \\
\hline
\end{tabular}

${ }^{1}$ Escala adotada de 0 a $100 \%$, sendo que: $0=$ ausência de intoxicação e $100=$ dano total à cultura do milho.

Tabela 4. Resultados médios de índice de colheita mecânica, população final, altura de plantas e inserção da $1^{0}$ espiga, obtidos no ensaio com herbicidas na cultura do milho. Rio Verde, GO. 1997/98.

\begin{tabular}{|c|c|c|c|c|c|}
\hline TRATAMENTO & $\begin{array}{l}\text { DOSE } \\
\text { (g/ha) }\end{array}$ & $\begin{array}{l}\text { ÍNDICE DE } \\
\text { COLHEITA } \\
\text { MECÂNICA }\end{array}$ & $\begin{array}{c}\text { POPULAÇÃO } \\
\text { (indivíduos) }\end{array}$ & $\begin{array}{c}\text { ALTURA } \\
\text { DE } \\
\text { PLANTAS }(\mathrm{cm})\end{array}$ & $\begin{array}{c}\text { ALTURA DA } \\
1^{0} \text { ESPIGA } \\
(\mathrm{cm})\end{array}$ \\
\hline Atrazine + metolachlor & $1400+2100$ & Excelente & $57 \mathrm{a}^{1}$ & $189,5 \mathrm{ab}$ & $102,0 \mathrm{a}$ \\
\hline Atrazine/metolachlor+nicosulfuron & $100 / 1500+12$ & Excelente & $58 \mathrm{a}$ & $794,5 \mathrm{a}$ & 103,7 a \\
\hline Atrazine/óleo+nicosulfuron & $1600+20$ & Excelente & $61 \mathrm{a}$ & $190,7 \mathrm{ab}$ & $103,5 \mathrm{a}$ \\
\hline Atrazine+nicosulfuron & $1000+40$ & Excelente & $58 \mathrm{a}$ & $186,2 \mathrm{ab}$ & 98,7 a \\
\hline Nicosulfuron & 50 & Médio & 58 a & $182,5 \mathrm{~b}$ & $97,2 \mathrm{a}$ \\
\hline Testemunha capinada & -- & Excelente & $54 \mathrm{a}$ & $190,5 \mathrm{ab}$ & $100,5 \mathrm{a}$ \\
\hline Testemunha sem capina & -- & Difícil & $56 \mathrm{a}$ & $187,0 \mathrm{ab}$ & $104,0 \mathrm{a}$ \\
\hline C.V. (\%) & -- & -- & 5,6 & 2,0 & 3,3 \\
\hline D. M. S. & -- & -- & 7,6 & 8,9 & 7,8 \\
\hline F (tratamento) & -- & -- & 1,8575 & 4,0644 & 2,5282 \\
\hline
\end{tabular}

${ }^{1}$ Médias na coluna seguidas das mesmas letras, não diferem significativamente entre si, pelo teste de Tukey a $5 \%$ de probabilidade

Tabela 5. Resultados médios de matéria seca das plantas daninhas e produção de grãos, obtidos no ensaio com herbicidas na cultura do milho. Rio Verde, GO. 1997/98.

\begin{tabular}{|c|c|c|c|c|}
\hline TRATAMENTO & $\begin{array}{l}\text { DOSE } \\
\text { (g/ha) }\end{array}$ & $\begin{array}{l}\text { MATÉRIA SECA DAS } \\
\text { PLANTAS DANINHAS } \\
\qquad\left(\mathrm{g} / \mathrm{m}^{2}\right)\end{array}$ & $\begin{array}{c}\text { RENDIMENTO } \\
\text { DE GRÃOS } \\
\text { (kg/ha) }\end{array}$ & $\begin{array}{c}\text { PRODUÇÃO } \\
\text { RELATIVA (\%) }\end{array}$ \\
\hline Atrazine + metolachlor & $1400+2100$ & $45,45 \mathrm{bc}$ & $7701 \mathrm{ab}^{1}$ & 96 \\
\hline Atrazine/metolachlor+nicosulfuron & $100 / 1500+12$ & $95,64 \mathrm{bc}$ & $7714 \mathrm{ab}$ & 97 \\
\hline Atrazine/óleo+nicosulfuron & $1600+20$ & $62,00 \mathrm{bc}$ & $8836 \mathrm{a}$ & 104 \\
\hline Atrazine+nicosulfuron & $1000+40$ & $16,85 \mathrm{c}$ & $8039 \mathrm{ab}$ & 101 \\
\hline Nicosulfuron & 50 & $130,88 \mathrm{~b}$ & $7365 \mathrm{ab}$ & 92 \\
\hline Testemunha capinada & -- & $9,78 \mathrm{c}$ & $7991 \mathrm{ab}$ & 100 \\
\hline Testemunha sem capina & -- & $336,50 \mathrm{a}$ & $6966 \mathrm{~b}$ & 87 \\
\hline C.V. $(\%)$ & -- & 45,3 & 7,4 & -- \\
\hline D. M. S. & -- & 105,26 & 1359 & -- \\
\hline F (tratamento) & -- & 25,056 & 2,46 & -- \\
\hline
\end{tabular}

${ }^{1}$ Médias na coluna seguidas das mesmas letras, não diferem significativamente entre si, pelo teste de Tukey a $5 \%$ de probabilidade.

emergência. Tais resultados são contrastantes àqueles obtidos por Silva (1998), em que aplicações de herbicidas em pósemergência sobre plantas daninhas de folhas largas de 4 a 7 folhas e as gramíneas de 1 a 2 perfilhos, reduziram de 2 a $5 \%$ a produção de grãos do milho, em relação à aplicação em préemergência.
A tendência para menor rendimento de grãos, obtida no presente trabalho com aplicação de herbicidas de pré-emergência, possivelmente se deve à presença de plantas infestantes dicotiledôneas, as quais apresentam tendência para melhor controle com as aplicações de herbicidas em pós-emergência. 


\section{CONCLUSÕES}

Os herbicidas atrazine + metolachlor $(1400+2100 \mathrm{~g} /$ ha), aplicados em pré-emergência; atrazine/metolachlor +nicosulfuron (1000/1500+12 g/ha), aplicados em pós-emergência precoce; atrazine/óleo vegetal +nicosulfuron $(1600+20$ $\mathrm{g} / \mathrm{ha}$ ), em pós-emergência normal e atrazine+nicosulfuron $(1000+40 \mathrm{~g} / \mathrm{ha}$, em pós-emergência tardia, proporcionaram eficiente controle das plantas daninhas corda-de-viola (Ipomoea grandifolia), leiteiro (Euphorbia brasiliensis) e trapoeraba (Commelina benghalensis). Nicosulfuron (50 g/ ha) apresentou eficiente controle das duas primeiras plantas daninhas, mas um controle deficiente da $C$. benghalensis.

Todos os herbicidas foram seletivos à cultura do milho.

\section{LITERATURA CITADA}

BARROS, A. C. de. Controle das plantas invasores no sistema de cultivo convencional do milho no Estado de Goiás. Goiânia, GO: EMGOPA-DID, 1993. 11 p. (EMGOPA, Comunicado Técnico, 39).

BARROS, A. C. de. Eficiência do herbicida atrazine em pósemergência-precoce no controle do jóa-de-capote, na cultura do milho. Goiânia, GO: EMGOPA-DID, 1994. 7 p. (EMGOPA, Comunicado Técnico, 46).

BARROS, A.C. de. Eficiência e seletividade do flumioxazin isolado e ou em misturas para a cultura do milho. Goiânia, GO: EMATER-GO, 1998. 16 p. (EMATERGO, Boletim de Pesquisa, 102).

BARROS, A.C. de; MENDONÇA, J.L. Efeitos de herbicidas pré-emergentes na cultura do milho em Jataí-GO. Goiânia, GO: EMGOPA-DID, 1991. 12 p. (EMGOPA, Boletim de Pesquisa, 20).

BARROS, A. C. de; OLIVEIRA, Z. J. de. Controle de plantas daninhas na cultura do milho, em solo sob vegetação de cerrado. Goiânia, GO: EMGOPA-DID, 1990. 10 p. (EMGOPA, Comunicado Técnico, 24).

CARVALHO, F. T.; CAVAZZANA, M. A.; GALBIATTI Jr., W. Eficiência e seletividade do herbicida isoxaflutole aplicado em pré-emergência na cultura do milho. In: CONGRESSO BRASILEIRO DA CIÊNCIAS DAS PLANTAS DANINHAS, 21, 1997, Caxambú. Resumos... Viçosa: SBCPD, 1997. p. 205.
FAHL, J. T.; CARELLI, M. L. C. Eficiência do nicosulfuron no controle do capim-massambará na cultura do milho. Planta Daninha, v. 15, n.1, p. 46-52, 1997.

FORSTER, R. Controle das plantas daninhas na cultura do milho. Campinas, SP: Fundação Cargil, 1991. 46 p. (Série Técnica, 5).

KISSMANN, K. G. Plantas infestantes e nocivas. Tomo II. São Paulo: BASF Brasileira, 1992. p. 550-553.

MEROTTO JÚNIOR A.; GUIDOLIN, A. F.; ALMEIDA, M. L. de.; HAVERROTH, H. S. Aumento da população de plantas e uso de herbicidas no controle de plantas daninhas em milho. Planta Daninha, v. 15, n.2, p. 141-151, 1997.

QUEIROZ, P. R. M. de; BARROS, A. C. de.; MOURA, E. Efeitos de herbicidas pré-emergentes no controle de plantas daninhas na cultura do milho (Zea mays L.), na região de Rio Verde-GO. In: CONGRESSO BRASILEIRO DA CIÊNCIA DAS PLANTAS DANINHAS, 21., 1997, Caxambú. Resumos... Viçosa: SBCPD, 1997. p.223.

ROSSI, I. H.; OSUNA, J. A.; ALVES, P. L. C. A.; REZUTTE, A. J. Interferência das plantas daninhas sobre algumas características agronômicas e a produtividade de sete cultivares de milho. Planta Daninha, v. 14, n. 2, p. 134-148, 1996.

RUCKHEIM FILHO, O.; VENTURELLA, L. R. C. Controle às plantas daninhas do milho. IPAGRO Informa , Porto Alegre, n. 17, p. 45-46, 1997.

SANTOS, C. A. L. dos.; ROZANSKI, A. Controle de plantas daninhas na cultura do milho (Zea mays $L$.), por meio de herbicidas. São Paulo, SP: CIBA GEIGY, s. d. n. p.

SILVA, J. B. da.; SILVA, A. F. Controle bem para colher melhor. Sinal Verde, São Paulo, v. 2, n. 4, p. 1213 ,

1997.

SILVA, J. B. da. Manejo de plantas daninhas na cultura do milho. In: CARVALHO. J. A.; CORREA, N. M. SEMINÁRIO SOBRE MANEJO DE PLANTAS DANINHAS NAS CULTURAS DA SOJA E DO MILHO, 1998, Uberlândia. Anais...Viçosa, MG: UFV, 1998. p. 35-37.

VIDAL, R. A. Herbicidas: mecanismo de ação e resistência de plantas. Porto Alegre, RS: R. A. VIDAL, 1997. 165 p. 